\title{
Comparative trial of iohexol 350, a non-ionic contrast medium, with diatrizoate (Urografin 370) in left ventriculography and coronary arteriography
}

\author{
I D SULLIVAN, R J WAINWRIGHT, J F REIDY, E SOWTON \\ From the Departments of Cardiology and Radiology, Guy's Hospital, London
}

SUMMARY In a prospective double blind randomised study in 25 consecutive patients a conventional ionic contrast medium (Urografin 370) was compared with the new non-ionic medium iohexol 350 (Omnipaque) in left ventriculography and coronary arteriography. In left ventriculography there was a clear patient preference for iohexol by both a visual analogue scale and independent observer assessment. Iohexol also induced a smaller increase in heart rate or decrease in systolic blood pressure than Urografin. In coronary arteriography iohexol resulted in a smaller reduction in heart rate and systolic blood pressure, a smaller maximum increase in $R R$ interval, less prolongation of the PQ and QT intervals and QRS duration, and a lower incidence of induced chest pain, ST segment depression, or $\mathrm{T}$ wave deflection.

Left ventriculography and coronary arteriography in patients investigated because of suspected coronary artery disease carry a low morbidity and very low mortality risk. 1 The left ventriculogram in most patients produces pain and heat sensation of a variable degree. The severity of the discomfort appears to be related to the degree of induced arteriolar dilatation, both of which are related to the osmolality of the contrast medium used, ${ }^{2}$ although their precise interrelation remains uncertain. The impairment of myocardial contractility which occurs after selective coronary arteriography is directly related to the osmolality and the chemistry of the contrast medium used, as are the electrocardiographic changes seen as a result of direct inhibition of sinoatrial node automaticity and atrioventricular nodal conductivity and conduction delay in distal portions of the Purkinje network. ${ }^{3}$

The first non-ionic and low osmolality contrast medium metrizamide (Amipaque) was produced as long ago as 1972. Clinical studies showed that it was associated with less patient discomfort after left ventriculography ${ }^{4}$ and with fewer $\mathrm{T}$ wave abnormalities ${ }^{4}$ and less chest pain ${ }^{5}$ after coronary arteriography when compared with ionic contrast media. Its major draw-

Requests for reprints to Dr E Sowton, Department of Cardiology, Guy's Hospital, London SE1 9RT.

Accepted for publication 12 January 1984 backs, however, were its instability in aqueous solution and its very high cost. More recently, stable solutions of three different low osmolality contrast media have been developed. The ionic mono-acid dimer Hexabrix (Guerbet) was found to be associated with less patient discomfort during left ventriculography than the conventional ionic contrast media but with similar $\mathrm{T}$ wave changes during coronary arteriography when compared with Urografin 370 and with more $T$ wave changes than Triosil or metrizamide. ${ }^{6}$ The nonionic compound iopamidol-(Niopam, E Merck Ltd) achieved greater patient tolerance and a significantly smaller increase in peripheral arterial blood flow than a conventional ionic contrast medium in lumbar aortography. ${ }^{7}$ Its use in a non-randomised open study has also shown less patient discomfort after left ventriculography, a smaller decrease in systolic blood pressure and heart rate, and fewer $T$ wave electrocardiographic changes after selective coronary arteriography. ${ }^{8}$

The aim of this study was to compare non-ionic iohexol 350 and the conventional diatrizoate contrast medium Urografin 370 in left ventriculography and coronary arteriography. Differences between the two media in patient tolerance, objective haemodynamic changes after left ventricular angiography, and electrocardiographic changes were determined after selective coronary arteriography in a prospective double blind randomised crossover trial. 


\section{Patients and methods}

Twenty five consecutive patients undergoing routine left ventriculography and selective coronary arteriography for investigation of chest pain were included in the study. Patients with unstable angina, previous coronary artery bypass surgery, or valvular heart disease were excluded. There were 22 men and three women, age range 22-74 (mean 50.7) years.

Standard Sones catheterisation techniques were used. Normal drug treatment was withheld on the day of the investigation. Premedication was with $10 \mathrm{mg}$ oral diazepam. A CM5 bipolar electrocardiographic rhythm strip was monitored continuously. Two left ventricular angiograms were performed in the $30^{\circ}$ right anterior oblique plane, once with iohexol 350 (Omnipaque, Nyegaard (UK) Ltd), and once with meglumine and sodium diatrizoate (Urografin 370, Schering Chemicals Ltd), the sequence being determined randomly. The same volume of contrast medium and rate of injection $(35 \mathrm{ml}$ at $8 \mathrm{ml} / \mathrm{s})$ and similar catheter position were used in each case.

\section{VENTRICULOGRAPHY}

Patients were warned to expect a "warm feeling" after left ventriculography and that they would be asked subsequently to assess this sensation. After the second left ventricular angiogram subjective patient responses to each were graded on as: 0 , no discomfort; 1, mild heat or pain; 2, moderate heat or pain; 3, distress or nausea or both; and 4, vomiting or retching or both. Each patient was then asked to grade "discomfort" associated with each of the left ventricular angiograms on a 0 (no discomfort) to 100 (intolerable discomfort) visual analogue scale. Heart rate, systolic blood pressure, and left ventricular end diastolic pressure were measured before each left ventricular angiogram and immediately, one, two, and three minutes after. There was a delay of $10-15 \mathrm{~s}$ in obtaining the "immediate" recordings while the catheter was flushed with saline and reconnected to the manometer line. Heart rate was calculated from the mean of 10 consecutive cycle lengths and left ventricular end diastolic and systolic pressures from the mean of five consecutive cycle lengths. Left ventricular end diastolic pressure was measured after the "a" wave, all 25 patients being in sinus rhythm.

\section{CORONARY ARTERIOGRAPHY}

Two selective right coronary artery injections were then given once with each medium, the sequence being determined randomly. After this, two selective left coronary artery injections were given once with each contrast medium, the sequence being reversed. Catheter blood pressure and the CM5 rhythm strip were recorded at a paper speed of $50 \mathrm{~mm} / \mathrm{s}$ before, during, and after each coronary injection. Heart rate and systolic blood pressure were recorded as mean values calculated from 10 consecutive cycles before and immediately after each injection. PQ, QRS, and QT intervals were measured as the mean of the three highest values from the 10 cycles immediately before and after each injection. The maximum increase in RR interval was also noted. Maximum ST segment depression measured $0.08 \mathrm{~s}$ after the end of the QRS complex and $\mathrm{T}$ wave deflection were each considered significant if there was a change of at least $0.1 \mathrm{mV}$ compared with the preceding rhythm strip. The induction of angina-like chest pain with specific coronary injections was noted.

The same rate of injection and volume of contrast medium were used for each injection into a particular coronary artery. There was a minimum delay of $45 \mathrm{~s}$ between successive coronary injections, longer if the CM5 rhythm strip had not regained its baseline pattern.

Catheterisation procedures were all performed by the same operator, and patient subjective responses elicited by a single (different) observer. The only person aware of the sequence of administration of the contrast media was the nurse. The code was not broken until data collection was complete. Angiographic film quality was independently assessed by comparing the matched left ventricular angiograms.

\section{STATISTICAL ANALYSIS}

Statistical evaluation of paired data was by Student's paired $t$ test. Differences between proportions were assessed by the $\chi^{2}$ method with Yates's correction.

\section{Results}

All 25 catheterisation procedures were completed without major complications. In one patient the second left ventriculogram caused intramyocardial staining with contrast medium; this pair of left ventriculograms was excluded from subsequent analysis of patient subjective response. Catheter tip systolic blood pressure fell below $80 \mathrm{~mm} \mathrm{Hg}$ in two patients when the right coronary artery was selectively cannulated. As it was not considered safe to leave the catheter tip in situ for prolonged periods changes in systolic blood pressure after selective right coronary injections in these two patients were excluded from analysis.

Table 1 Patients' visual analogue assessment (range 0-100) of discomfort induced by left ventriculography using iohexol or Urografin. Values are means $\pm S D$

\begin{tabular}{lll}
\hline Iohexol & Urografin & $p$ \\
\hline $33.7 \pm 18.1$ & $49.5 \pm 23.2$ & $<0.001$ \\
\hline
\end{tabular}




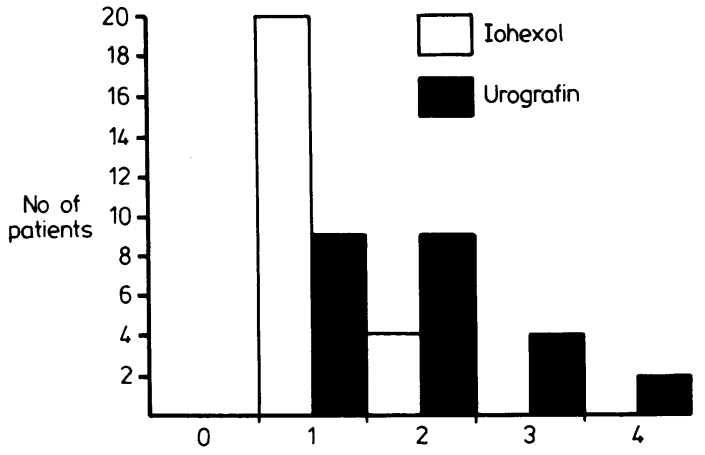

Figure Observer's assessment of patient discomfort during left ventriculography using iohexol or Urografin, assessed on scale: 0 , no discomfort; 1 , mild heat or pain; 2 , moderate heat or pain; 3 , distress or nausea or both; 4 , vomiting or retching or both.

Twenty two patients had coronary artery disease; three (two men, one woman) had angiographically normal coronary arteries. One of the latter, the youngest patient in the series, had hypertrophic cardiomyopathy.

When the paired and matching left ventricular angiograms were reviewed no difference in image quality could be detected. The iodine concentration of the iohexol $(350 \mathrm{mg} / \mathrm{ml})$ was slightly lower than that of the Urografin $(370 \mathrm{mg} / \mathrm{ml})$.

There was a clear patient preference for iohexol in left ventriculography, as judged by the patients' own visual analogue assessment of the discomfort induced (Table 1) and by observer grading (Figure). On the visual analogue scale 21 patients indicated less discomfort with iohexol, with only two preferring Urografin and one detecting no difference between the two media.

The reduction in systolic blood pressure and the increase in heart rate occurring immediately after left ventriculography were more pronounced with Urografin than with iohexol (Table 2). The immediate increase in left ventricular end diastolic pressure was similar for each of the contrast media but greater after Urografin at two $(p<0.05)$ and three (NS) minutes after left ventriculography (Table 2). The mean number of extrasystoles during left ventriculography and for a period of 10 seconds thereafter was similar for each of the contrast media: $6.8 \pm 3.5$ (mean $\pm S D$ ) for iohexol and $5 \cdot 7 \pm 4.0$ for Urografin. There were greater numbers of patients with chest pain, ST segment depression, or $\mathrm{T}$ wave deflection induced by selective coronary artery injections of Urografin than of iohexol, although the difference was statistically significant only in the latter (Table 3). Reductions in heart rate and systolic blood pressure, each measured as mean values of 10 cycles before and immediately after coronary injections, and maximum increase in RR intervals were all greater with Urografin than with iohexol, the differences being highly significant after left coronary arteriography (Table 4).

There were also major differences in induced conduction changes between the two media. The QT and

Table 2 Increases in left ventricular end diastolic pressure, systolic blood pressure, and heart rate expressed as mean percentage increase $( \pm S D)$ of values before ventriculography, induced up to 3 minutes after left ventriculography using iohexol or Urografin

\begin{tabular}{|c|c|c|c|c|c|c|c|c|}
\hline & \multicolumn{8}{|c|}{ Time after left ventriculogram } \\
\hline & \multicolumn{2}{|l|}{ Immediately } & \multicolumn{2}{|l|}{$1 \min$} & \multicolumn{2}{|l|}{$2 \min$} & \multicolumn{2}{|l|}{$3 \min$} \\
\hline & Iohexol & Urografin & Iohexol & Urografin & Iohexol & Urografin & Iohexol & Urografin \\
\hline $\begin{array}{l}\text { Left ventricular } \\
\text { end diastolic } \\
\text { pressure }\end{array}$ & $23 \cdot 5 \pm 36 \cdot 7$ & $14 \cdot 4 \pm 25.0$ & $26 \cdot 2 \pm 36 \cdot 6$ & $34.0 \pm 30.6$ & $14 \cdot 4 \pm 25 \cdot 8$ & $33 \cdot 2 \pm 36 \cdot 4^{\star}$ & $10.7 \pm 27.7$ & $23 \cdot 8 \pm 20.8$ \\
\hline Systolic blood & $-1 \cdot 7 \pm 10.4$ & $-12 \cdot 0 \pm 13 \cdot 8^{\star \star}$ & $1 \cdot 7 \pm 8 \cdot 3$ & $0.3 \pm 8.9$ & $1.5 \pm 10.0$ & $1.7 \pm 10.1$ & $2 \cdot 8 \pm 8 \cdot 2$ & $0.0 \pm 11.4$ \\
\hline Heart rate & $6.4 \pm 8.4$ & $21 \cdot 3 \pm 16 \cdot 0^{\star \star}$ & $4 \cdot 9 \pm 8 \cdot 6$ & $11 \cdot 2 \pm 12 \cdot 2$ & $4 \cdot 1 \pm 8 \cdot 3$ & $8 \cdot 7 \pm 11 \cdot 0$ & $1 \cdot 6 \pm 7.8$ & $5.9 \pm 10.5$ \\
\hline
\end{tabular}

${ }^{\star} \mathrm{p}<0.05$.

$\star_{\star \star} \mathrm{p}<0.001$

Table 3 Number of patients with chest pain, ST segment depression, or $T$ wave deflection induced by selective right or left coronary artery injection of iohexol or Urografin

\begin{tabular}{|c|c|c|c|c|c|c|}
\hline & \multicolumn{2}{|c|}{ Right coronary artery } & \multicolumn{2}{|c|}{ Left coronary artery } & \multicolumn{2}{|l|}{ Total } \\
\hline & Iohexol & Urografin & Iohexol & Urografin & Iohexol & Urografin \\
\hline $\begin{array}{l}\text { Chest pain } \\
\text { ST depression }(\geqslant 0.1 \mathrm{mV}) \\
\text { T wave deflection }(\geqslant 0.1 \mathrm{mV})\end{array}$ & $\begin{array}{l}5 \\
1 \\
0\end{array}$ & $\begin{array}{l}8 \\
2 \\
11\end{array}$ & $\begin{array}{l}7 \\
9 \\
11\end{array}$ & $\begin{array}{l}9 \\
16 \\
18\end{array}$ & $\begin{array}{l}12 \\
10 \\
11\end{array}$ & $\begin{array}{l}17 \\
18 \\
29 \star\end{array}$ \\
\hline
\end{tabular}

${ }^{\star} \mathrm{p}<0.001$. 
Table 4 Reduction in heart rate and systolic blood pressure, maximum increase in $R R$ interval, expressed as mean percentage change $( \pm S D)$ of preinjection value, and prolongation of $P Q$ interval, $Q R S$ duration, and $Q T$ interval, expressed as mean percentage increase $( \pm S D)$ of preinjection value, induced by selective right or left coronary artery injections of iohexol or Urografin

\begin{tabular}{|c|c|c|c|c|}
\hline & \multicolumn{2}{|c|}{ Right coromary artery } & \multicolumn{2}{|c|}{ Left coromary artery } \\
\hline . & Iohexol & Urografin & Iohexol & Urografin \\
\hline $\begin{array}{l}\text { Heart rate reduction } \\
\text { Systolic blood pressure reduction } \\
\text { Maximum increase in } R \mathbf{R} \text { interval } \\
\text { Prolongation of: }\end{array}$ & $\begin{array}{l}2 \cdot 7 \pm 5 \cdot 3 \\
1 \cdot 0 \pm 7 \cdot 5 \\
8 \cdot 0 \pm 8 \cdot 6\end{array}$ & $\begin{array}{l}5 \cdot 7 \pm 7 \cdot 1 \\
3 \cdot 4 \pm 8 \cdot 7 \\
13 \cdot 5 \pm 17 \cdot 9\end{array}$ & $\begin{array}{l}3 \cdot 6 \pm 5 \cdot 0 \\
4 \cdot 2 \pm 7 \cdot 4 \\
9 \cdot 9 \pm 11 \cdot 3\end{array}$ & $\begin{array}{l}11 \cdot 2 \pm 9 \cdot 1^{\star \star \star} \\
15 \cdot 3 \pm 9 \cdot 8^{\star \star \star} \\
33 \cdot 9 \pm 30 \cdot 2^{\star \star}\end{array}$ \\
\hline $\begin{array}{l}\text { PQ interval } \\
\text { QRS duration } \\
\text { QT interval }\end{array}$ & $\begin{array}{l}1 \cdot 5 \pm 4 \cdot 8 \\
5 \cdot 5 \pm 8 \cdot 3 \\
3 \cdot 8 \pm 4 \cdot 4\end{array}$ & $\begin{array}{l}5 \cdot 9 \pm 6 \cdot 4^{\star} \\
6 \cdot 6 \pm 7 \cdot 9 \\
12 \cdot 0 \pm 11 \cdot 2^{\star \star}\end{array}$ & $\begin{array}{l}1 \cdot 6 \pm 4 \cdot 0 \\
13 \cdot 6 \pm 15 \cdot 1 \\
5 \cdot 7 \pm 4 \cdot 1\end{array}$ & $\begin{array}{l}6 \cdot 2 \pm 6 \cdot 3^{\star \star} \\
23 \cdot 3 \pm 18 \cdot 5^{\star} \\
19 \cdot 3 \pm 13 \cdot 3^{\star \star \star}\end{array}$ \\
\hline
\end{tabular}

${ }^{\star} \mathrm{p}<0.05$.

$\star \star \mathrm{p}<0.01$

$\star \star \star \mathrm{p}<0.001$.

PQ intervals and QRS duration after left coronary arteriography and the $Q T$ and $P Q$ intervals after right coronary injections were significantly more prolonged with Urografin than with iohexol (Table 4). The differences in the degree of prolongation of the QT interval were most pronounced.

\section{Discussion}

The haemodynamic and electrocardiographic findings during coronary arteriography are in keeping with reports that impairment of myocardial contractility and induced conduction tissue abnormalities are largely dependent on the hyperosmolality of the contrast medium. ${ }^{3}$ Studies with iohexol in dogs ${ }^{9} 10$ have reported similar findings.

A definite patient preference for left ventriculography using lower osmolality contrast media of both ionic $^{6}$ and non-ionic ${ }^{8}$ composition has previously been shown. In addition, the present study indicates that there is less alteration of the resting haemodynamic state with a non-ionic contrast medium.

The clinical significance of the electrocardiographic changes induced by coronary arteriography is imprecise. In particular, there has been no definite correlation between any of the observed changes in the electrocardiogram and the induction of ventricular fibrillation. ${ }^{3} \mathrm{~A}$ relation between the degree of prolongation of the QT interval and the likelihood of ventricular fibrillation has, however, been noted in dog coronary arteriography, ${ }^{11}$ both of which occurred significantly less frequently with a non-ionic low osmolality contrast medium. The occurrence of serious ventricular arrhythmias in patients with long QT intervals is well known clinically. The greater increase in QT interval, however, occurred in this study after left rather than right coronary artery injections. Ventricular fibrillation during clinical coronary arteriography is reported to occur more frequently after selective right, rather than left, coronary artery injections, ${ }^{12}$ which suggests that prolongation of the QT interval may not be the most important factor in its genesis.

A theoretical disadvantage of the low osmolality contrast media in coronary arteriography may be a smaller increase in coronary blood flow compared with that with conventional contrast media owing to the less pronounced vasodilatory effect. This increased flow has been thought to minimise the time the contrast medium is in the coronary circulation, ${ }^{3}$ and an increased coronary transit time has been reported for metrizamide compared with that for conventional ionic media in man. ${ }^{5}$ Coronary transit time was measured from the cine film as the time from the start of the contrast medium injection into the left coronary artery until the appearance of contrast medium in the first part of the coronary sinus. A study in dogs, however, showed that metrizamide was cleared more rapidly both from the coronary arteries and from the coronary sinus than a conventional ionic contrast medium despite producing a smaller increase in coronary flow. ${ }^{13}$ One possible explanation is slower clearance of the highly deformed erythrocytes which result from exposure to the hyperosmolar medium and which are less easily able to pass through capillaries.

Another potential benefit of these new contrast media may be a reduction in "allergic" or hypersensitivity reactions. Both iopamidol and iohexol have been shown to induce significantly less bronchospasm than an ionic medium of higher osmolality when injected intravenously. ${ }^{14}$

In this study iohexol was clearly preferred to Urografin by patients undergoing left ventriculography and induced fewer haemodynamic and electrocardiographic changes during coronary arteriography. Most of the patients experienced only mild or moderate discomfort after left ventriculography with Urografin, although the total volume and rate of injection of contrast medium used for each left ventriculogram were less than those routinely used in 
many other centres. The electrocardiographic and haemodynamic changes seen after coronary arteriography using the same agent did not induce arrhythmias or other complications in any patient, which is in keeping with common clinical experience. Hence, it is possible that the routine use of the more expensive lower osmolality media may not be currently justified in every patient undergoing left ventriculography and coronary arteriography but may be indicated in selected patients such as those with compromised haemodynamic states, unstable angina, acute myocardial infarction, history of allergy or previous adverse reaction to contrast medium, impaired renai function, and those undergoing transluminal coronary angioplasty or receiving large volumes of contrast medium.

We thank Nyegaard (UK) Ltd for providing iohexol 350 , and the cardiac catheter laboratory staff for their cooperation in this study.

\section{References}

1 Anonymous. Risks of coronary arteriography. [Editorial]. Br Med F 1980; 281: 627-8.

2 Dawson P, Grainger RG, Pitfield J. The new low osmolar contrast media: a simple guide. Clin Radiol 1983; 34: 221-6.

3 Fischer HW, Thomson KR. Contrast media in coronary arteriography: a review. Invest Radiol 1978; 13: 450-9.

4 Cumberland DC. Amipaque in coronary angiography and left ventriculography. Br $\mathcal{F}$ Radiol 1981; 54: 203-6.
5 Enge I, Nitter-Hauge S, Andrew E, Levorstad K. Amipaque: a new contrast medium in coronary angiography. Radiology 1977; 125: 317-22.

6 Cumberland DC. Hexabrix - a new contrast medium in angiocardiography. Br Heart f 1981; 45: 698-702.

7 Padayachee TS, Reidy JF, King DH, Reeves M, Gosling RG. Femoral artery flow and pain during lumbar aortography: comparison of ionic and non-ionic contrast media. Clin Radiol 1983; 34: 79-85.

8 Partridge JB, Robinson PJ, Turnbull CM, Stoker JB, Boyle RM, Morrison GW. Clinical cardiovascular experiences with iopamidol: a new non-ionic contrast medium. Clin Radiol 1981; 32: 451-5.

9 Trägärdh B. Coronary angiography with iohexol and other contrast media in the dog. I Electrocardiographic alterations. Acta Radiol [Suppl] (Stockh) 1980; suppl 362: 17-20.

10 Trägärdh B, Cederlund CG. Coronary angiography with iohexol and other contrast media in the dog. III Contractility of the left ventricle. Acta Radiol [Suppl] (Stockh) 1980; suppl 362: 25-7.

11 Trägärdh B, Lynch PR. ECG changes and arrhythmias induced by ionic and non-ionic contrast media during coronary arteriography in dogs. Invest Radiol 1978; 13: 233-7.

12 Ross RS, Gorlin R. Co-operative study on cardiac catheterization. Coronary arteriography. Circulation 1968; 37: suppl III: 67-73.

13 Trägärdh $B$, Lynch $P$, Trägärdh $M$. Coronary angiography with diatrizoate and metrizamide. Comparison of ionic and non-ionic contrast medium effect on coronary blood flow in dogs. Acta Radiol [Diagn] (Stockh) 1976; 17: 69-80.

14 Dawson P, Pitfield J, Britton J. Contrast media and bronchospasm: a study with iopamidol. Clin Radiol 1983; 34: 227-30. 